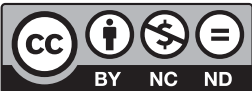

Estudos Teológicos foi licenciado com uma Licença Creative Commons Atribuição - NãoComercial - SemDerivados 3.0 Não Adaptada

http://dx.doi.org/10.22351/et.v60i1.3921

\title{
AS RELIGIÕeS E A RECONSTRUÇÃO DOS DIREITOS HUMANOS: UMA ABORDAGEM TRANSDISCIPLINAR ${ }^{1}$ \\ Religions and reconstruction of human rights: a transdisciplinary approach
}

\section{Gilbraz Aragão Mailson Fernandes Cabral de Souza $^{3}$}

Resumo: Os direitos humanos têm um importante papel na construção e promoção de uma cultura de paz. Apesar disso, eles têm sido postos em questão face aos grandes conflitos da contemporaneidade, tais como crise migratória, violência urbana e a ascensão de fundamentalismos políticos e religiosos ao redor do globo. Procurando colaborar para uma reflexão sobre esse impasse, o presente ensaio busca articular a concepção contra-hegemônica dos direitos humanos delineada por Boaventura de Sousa Santos, o conceito de pluralismo religioso, tal como teorizado por Peter Berger e a abordagem transdisciplinar desenvolvida por Basarab Nicolescu. Sustentamos que as religiões podem fornecer, por meio de suas teologias pluralistas e progressistas, uma nova plataforma para a reconstrução dos direitos humanos, engendrando uma atitude transcultural e transreligiosa para a reconstrução dos direitos humanos.

Palavras-chave: Pluralismo. Direitos humanos. Transdisciplinaridade.

\begin{abstract}
Human rights play an important role in building and promoting a culture of peace. Despite this, they have been called into question in the face of the great conflicts of contemporary times, such as the migratory crisis, urban violence and the rise of political and religious fundamentalism around the globe. In an attempt to collaborate for a reflection on this impasse, this essay aims to articulate the counter-hegemonic conception of human rights outlined by Boaventura de Sousa Santos, the concept of religious pluralism, as theorized by Peter Berger and the transdisciplinary approach developed by Basarab Nicolescu. We sustain that religions can provide, through their pluralistic and progressive theologies, a new platform for the reconstruction of human rights, engendering a cross-cultural and trans-religious attitude for a reconstruction of human rights. Keywords: Pluralism. Human rights. Transdisciplinarity.
\end{abstract}

1 O artigo foi recebido em 02 de março de 2020 e aprovado em 13 de abril de 2020 com base nas avaliações dos pareceristas ad hoc.

2 Doutor em Teologia. Universidade Católica de Pernambuco (UNICAP). E-mail: gil_braz@uol.com.br

3 Mestre em Ciências da Religião. Universidade Católica de Pernambuco (UNICAP). E-mail: mailsoncabral@ yahoo.com.br 


\section{Introdução}

Passados mais de setenta anos desde a promulgação da Declaração Universal dos Direitos Humanos - em que os horrores causados pela Segunda Guerra Mundial parecem ter se distanciado da memória e da experiência política contemporânea de muitos países -, os direitos humanos têm encontrado dificuldades para sua efetivação. Um rápido sobrevoo no globo nos fornece os indícios: vários países europeus relutantes em honrar sua obrigação de oferecer asilo aos milhares de imigrantes e refugiados em suas fronteiras; ausência de garantia das condições mínimas de existência nos contextos urbanos das grandes metrópoles na América Latina; no Oriente Médio, em países como Síria e Iêmen, civis são bombardeados ou morrem de fome, e os médicos e hospitais que tentam prestar assistência aos feridos têm sido atacados por todos os lados dos conflitos.

$\mathrm{Na}$ atual geopolítica, o ideário de diminuir as barreiras e promover o respeito entre os povos foi gradualmente substituído pela construção de muros para impedir o avanço daqueles julgados como indesejáveis. Diante desse quadro, a geografia política internacional distancia-se das ideias de justiça que outrora animaram a construção dos direitos humanos. Além disso, a atitude das pessoas em relação aos direitos humanos também está em trânsito. Os princípios subjacentes aos direitos humanos parecem continuar válidos para muitos, porém o respeito a esses direitos parece ser cada vez mais relativizado e diminuído. ${ }^{4}$

Há um descuido e um descaso imenso pela sorte dos desempregados e aposentados, sobretudo dos milhões e milhões de excluídos do processo de produção, tidos como descartáveis e zeros econômicos. Esses nem sequer ingressam no exército de reserva do capital. Perderam o privilégio de serem explorados a preço de um salário mínimo e de alguma seguridade social. Há um descuido e descaso pela coisa pública. Organizam-se políticas pobres para os pobres; os investimentos sociais em seguridade alimentar, em saúde, em educação e em moradia são, em geral, insuficientes. Há um descuido vergonhoso pelo nível moral da vida pública marcada pela corrupção e pelo jogo explícito de poder de grupos, chafurdados no pantanal de interesses corporativos. Há um descuido e um descaso na salvaguarda de nossa casa comum, o planeta Terra. Solos são envenenados, ares são contaminados, águas são poluídas, florestas são dizimadas, espécies de seres vivos são exterminadas; um manto de injustiça e de violência pesa sobre dois terços da humanidade. ${ }^{5}$

Diante desse quadro, que linguagem pode se conectar à experiência comum das pessoas, dialogando e reafirmando o valor dos direitos humanos em nossos tempos? A fim de responder a esse questionamento, propomos a seguinte tese: para que os direitos humanos exerçam o papel de gramática de dignidade humana, é necessário que eles sejam pensados sob uma perspectiva contra-hegemônica, isto é, a partir

4 Cf. BBC. Estamos indo em direção a um mundo sem direitos humanos? BBC Brasil. 07 jan. 2017. Disponível em: <https:/www.bbc.com/portuguese/internacional-38510456>. Acesso em: 20 jan. 2020.

5 BOFF, Leonardo. Saber cuidar: ética do humano, compaixão pela Terra. Petrópolis: Vozes, 1999. p. 18. 
das lutas por justiça socioeconômica, histórica e cultural. Nesse sentido, as religiões, por meio de suas teologias pluralistas e progressistas, podem fornecer um ponto de intersecção, sendo uma fonte de energia para as lutas por transformação social e humanização da história.

Tomando essa direção, o presente texto é uma tentativa inicial de articulação entre a concepção contra-hegemônica dos direitos humanos delineada por Boaventura de Sousa Santos ${ }^{6}$, o pluralismo religioso, tal como teorizado por Peter Berger ${ }^{7}$ e a abordagem transdisciplinar desenvolvida por Basarab Nicolescu ${ }^{8}$. O intuito é o de colaborar para uma reflexão sobre a questão, a fim de engendrar uma atitude transcultural e transreligiosa nos estudos de religião e sua interface com os direitos humanos.

\section{Uma breve genealogia dos direitos humanos}

Os direitos humanos podem ser agrupados em três gerações, que historicamente englobam e expandem os direitos adquiridos por suas predecessoras. A primeira centrou-se nas liberdades individuais e nos direitos civis, consagrados no século XVIII, com o surgimento do capitalismo; a segunda destacou-se pelos direitos sociais ligados ao mundo do trabalho, no século XIX e nas primeiras décadas do século XX; a terceira, em meados do século XX em diante, notabilizou-se pelo direito das coletividades, a defesa da ecologia, além de desenvolvimento, autodeterminação dos povos e a partilha do patrimônio técnico-científico e cultural. ${ }^{9}$

Na contemporaneidade, os direitos humanos emergem como um campo distinto do direito internacional no contexto pós-Segunda Guerra Mundial por meio da Declaração Universal dos Direitos Humanos, promulgada em 1948, inserindo a perspectiva de uma ética universalista no ordenamento jurídico de diferentes Estados. Para a Organização das Nações Unidas (ONU), os direitos humanos são universais e inalienáveis, sendo fundados sobre o respeito pela dignidade e valor da pessoa humana:

Os direitos humanos são comumente entendidos como sendo aqueles direitos que são inerentes ao ser humano. O conceito de direitos humanos reconhece que cada ser humano tem o direito de desfrutar de seus direitos humanos, sem distinção de raça, cor, sexo, língua, religião, opinião política ou outra, de origem nacional ou social, riqueza, nascimento ou qualquer outra condição ${ }^{10}$.

\footnotetext{
SANTOS, Boaventura de Sousa. Se Deus fosse um ativista dos direitos humanos. São Paulo: Cortez, 2014. BERGER, Peter. Os múltiplos altares da modernidade: rumo a um paradigma da religião numa época pluralista. Petrópolis: Vozes, 2017.

8 NICOLESCU, Basarab. O manifesto da transdisciplinaridade. São Paulo: Triom, 1999.

9 BENEVIDES SOARES, Maria. Cidadania e Direitos Humanos. CP Cadernos de Pesquisa, Fundação Carlos Chagas, São Paulo, n. 104, p. 39-46, jul. 1998. Disponível em: <publicacoes.fcc.org.br/ojs/index. $\mathrm{php} / \mathrm{cp} /$ article/view/715/731>. Acesso em: 05 maio 2019.

${ }^{10}$ UNITED NATIONS. ABC: teaching human rights, practical activities for primary and secondary schools. Gevena: United Nations Publications, 2004. p. 142.
} 
Os direitos humanos tornaram possível a universalização dos direitos civis e políticos e a internacionalização da noção de que um indivíduo pode ser sujeito do Direito além das jurisdições estatais. A seguridade desses direitos tornou-se uma discussão jurídica, perpassando as relações entre os Estados. ${ }^{11}$ Não obstante, é importante ressaltar que a declaração é um documento de caráter recomendatório e que, mesmo tendo sido ratificada por muitos países, isso não garantiu o reconhecimento dos pactos que a compõem.

Nesse sentido, os direitos humanos diferenciam-se dos direitos do cidadão. Os primeiros são de caráter universal, supraestatal, ao passo que os segundos dependem de uma ordem jurídico-política de um país para que possam ser efetivados, definindo por meio de uma Constituição quem é cidadão ou não. ${ }^{12}$ Assim, o reconhecimento dos direitos humanos em uma legislação é dependente de que o Estado lhe seja signatário e, efetivamente, aderente.

No Brasil, os direitos humanos emergiram na arena pública no contexto das lutas sociais contra a ditadura militar, no entanto só entraram de fato para a agenda política nacional a partir da Constituição de 1988. A Carta Magna assumiu a qualidade de marco jurídico da transição democrática e da institucionalização dos direitos humanos. ${ }^{13}$ A partir desse período, diversos tratados internacionais ${ }^{14}$ de proteção aos direitos humanos passaram a ser ratificados pelo Brasil. A respeito da recepção desses tratados, a Emenda Constitucional n. 45/2004 acrescenta um terceiro parágrafo ao artigo $\mathrm{V}$ da Constituição Federal, prescrevendo que na ordem jurídica brasileira: "Os tratados e convenções internacionais sobre direitos humanos aprovados, em cada Casa do Congresso Nacional, em dois turnos, por três quintos dos votos dos respectivos membros, serão equivalentes às emendas à Constituição" 15 .

${ }^{11}$ Cf. LOGHI, Carla. Direitos Humanos e cidadania. Projeto História, v. 51, p. 7-14, set./dez. 2014. Disponível em: <revistas.pucsp.br/index.php/revph/article/viewFile/24045/17587>. Acesso em: 19 maio 2019.

${ }^{12}$ Cf. BENEVIDES SOARES, 1998.

${ }^{13}$ Cf. PIOVESAN, Flávia. Direitos humanos e direito constitucional internacional. Caderno de direito constitucional. Escola de magistratura do Tribunal Regional Federal da $4^{\mathrm{a}}$ região, 2006.

${ }^{14}$ É possível listar os tratados na seguinte ordem cronológica: a) a Convenção Interamericana para Prevenir e Punir a Tortura, em 20 de julho de 1989; b) a Convenção contra a Tortura e outros Tratamentos Cruéis, Desumanos ou Degradantes, em 28 de setembro de 1989; c) a Convenção sobre os Direitos da Criança, em 24 de setembro de 1990; d) o Pacto Internacional dos Direitos Civis e Políticos, em 24 de janeiro de 1992; e) o Pacto Internacional dos Direitos Econômicos, Sociais e Culturais, em 24 de janeiro de 1992; f) a Convenção Americana de Direitos Humanos, em 25 de setembro de 1992; g) a Convenção Interamericana para Prevenir, Punir e Erradicar a Violência contra a Mulher, em 27 de novembro de 1995; h) o Protocolo à Convenção Americana referente à Abolição da Pena de Morte, em 13 de agosto de 1996; i) o Protocolo à Convenção Americana referente aos Direitos Econômicos, Sociais e Culturais (Protocolo de San Salvador), em 21 de agosto de 1996; j) o Estatuto de Roma, que cria o Tribunal Penal Internacional, em 20 de junho de 2002; k) o Protocolo Facultativo à Convenção sobre a Eliminação de todas as formas de Discriminação contra a Mulher, em 28 de junho de 2002; e 1) os dois Protocolos Facultativos à Convenção sobre os Direitos da Criança, referentes ao envolvimento de crianças em conflitos armados e à venda de crianças e prostituição e pornografia infantis, em 24 de janeiro de 2004. A esses avanços soma-se o reconhecimento da jurisdição da Corte Interamericana de Direitos Humanos, em dezembro de 1998 (PIOVESAN, 2006, p. 28).

15 BRASIL. Constituição (1988). Brasília: Senado Federal, 2015. 
Para Piovesan, com base no segundo parágrafo ${ }^{16}$ do artigo $\mathrm{V}$ da Constituição, os direitos internacionais adquirem o status de norma constitucional:

[...] os direitos fundamentais podem ser classificados em três distintos grupos: a) o dos direitos expressos na Constituição; b) o dos direitos implícitos, decorrentes do regime e dos princípios adotados pela Carta constitucional; e c) o dos direitos expressos nos tratados internacionais subscritos pelo Brasil. A Constituição de 1988 inova, assim, ao incluir, dentre os direitos constitucionalmente protegidos, os direitos enunciados nos tratados internacionais de que o Brasil seja signatário. Ao efetuar tal incorporação, a Carta está a atribuir aos direitos internacionais uma natureza especial e diferenciada, qual seja a de norma constitucional ${ }^{17}$.

Assim, sob a forma da lei, está formalmente assegurada a presença dos direitos humanos no contexto constitucional brasileiro. Como pauta dos direitos humanos, a diversidade religiosa insere-se na garantia da liberdade de religião e crença - expresso no artigo XVIII da Declaração Universal dos Direitos Humanos. Nesse sentido, o respeito às espiritualidades da humanidade e a defesa da liberdade religiosa implicam, simultaneamente, o combate à intolerância religiosa e a proteção da diversidade que compõe o pluralismo religioso, reconhecendo-o como de importância fundamental na promoção de uma cultura de paz.

\section{Uma concepção contra-hegemônica dos direitos humanos}

Apesar dos avanços conquistados ao longo das últimas décadas, os direitos humanos encontram-se, atualmente, com sua popularidade e compreensão sensivelmente relativizadas no debate público. Em parte, isso é resultado de um desgaste histórico de uma política que foi projetada num contexto radicalmente diferente do atual. Por outro lado, isso se deve também ao fato de que os direitos humanos comportam contradições e limitações que colocam em xeque sua universalidade. Especialmente no caso das religiões, isso se torna mais evidente, posto que muitas das situações de conflitos ideológicos e políticos possuem justificativas de ordem religiosa - sejam elas de forma velada ou não.

Nesse sentido, a crítica desenvolvida por Santos ${ }^{18}$ torna-se pertinente ao debate. Ele argumenta que, independentemente de quão antigos sejam seus antecedentes históricos, os direitos humanos, como linguagem política de emancipação social, só entraram nas agendas nacionais e internacionais a partir das décadas de 1970 e 1980. Nessa época, entrou em pauta o direito das coletividades, a defesa ao meio ambiente, o desenvolvimento, a autodeterminação dos povos e a partilha do patrimônio técnico-

\footnotetext{
16 “Os direitos e garantias expressos nessa Constituição não excluem outros decorrentes dos regimes e dos princípios por ela adotados, ou dos tratados internacionais em que a República Federativa do Brasil seja parte" (BRASIL, 1988).

17 PIOVESAN, 2006, p. 29.

18 SANTOS, 2014.
} 
-científico e cultural. Ao analisar os fundamentos e o alcance dos direitos humanos, Santos afirma que quatro ilusões compõem o senso comum sobre os direitos humanos: a teleologia, o triunfalismo, a descontextualização e o monolitismo.

A teleologia traduz-se numa leitura da história como um percurso linear que direcionou a um consenso sobre os direitos humanos, e que esse entendimento significou um bem incondicional. Essa ilusão impediria a interpretação do passado como contingente, isto é, que em diferentes momentos históricos outras ideias estiveram em circulação. $\mathrm{O}$ fato de uma delas ter saído vitoriosa desse processo - os direitos humanos - é um produto contingente. Por isso os direitos humanos devem ser explicados $a$ posteriori e não como algo que poderia ser previsto deterministicamente.

O triunfalismo seria a compreensão de que o êxito dos direitos humanos é um bem incondicional da humanidade. Essa leitura tem como pressuposto que outras semânticas de dignidade humana que concorreram com os direitos humanos e que não os invocaram para justificar suas causas e suas lutas eram eticamente ou politicamente inferiores. ${ }^{19}$ São exemplos disso os movimentos de libertação anticoloniais do século $\mathrm{XX}$ e os movimentos socialista e comunista. $\mathrm{O}$ fato de que outras linguagens de lutas por justiça social terem sido preteridas pelos direitos humanos só pode ser tomado como algo positivo se se demonstrar que os direitos humanos possuem um mérito que não se deduza apenas do fato de terem saído vencedores - o triunfo dos direitos humanos pode significar progresso para uns e retrocesso para outros.

A descontextualização consiste em não considerar que os direitos humanos foram usados em contextos diversos e com objetivos controversos como discurso e arma política, legitimando, inclusive, práticas de violação dos seus próprios preceitos. A esse respeito, Santos argumenta que quando o discurso dos direitos humanos se separou da tradição revolucionária, em meados do século XIX, ele passou a ser trabalhado como uma gramática despolitizada de transformação social: "Os direitos humanos foram subsumidos no direito do Estado, e o Estado assumiu o monopólio da produção do direito e de administração da justiça" 20 .

O monolitismo seria a negação das tensões e das contradições internas nas teorias dos direitos humanos, decorrente de uma ambiguidade com os direitos do cidadão. Os direitos humanos referem-se a uma coletividade mais inclusiva, a humanidade, ao passo que os direitos do cidadão remetem à coletividade dos cidadãos de um determinado Estado. Os direitos humanos são geralmente evocados quando há alguma violação grave dos direitos de cidadania: "Os direitos humanos surgem como o patamar mais baixo de inclusão, um movimento descendente da comunidade mais densa de cidadãos para a comunidade mais diluída de humanidade"21. Um conflito que ilustra o problema do monolitismo é a tensão entre os direitos individuais e coletivos. A Declaração Universal dos Diretos Humanos, por exemplo, só reconhece dois tipos de sujeitos jurídicos: o indivíduo e o Estado. As coletividades que não possuíam Es-

\footnotetext{
19 Cf. SANTOS, 2014.

${ }^{20}$ SANTOS, 2014, p. 21.

${ }^{21}$ SANTOS, 2014, p. 22.
} 
tado estavam ausentes na concepção original do documento. Ficaram de fora da pauta dos direitos humanos as questões relativas à dominação coletiva, para as quais os direitos individuais não ofereciam proteção. Só em meados dos anos de 1960 as lutas anticoloniais entram na agenda das Nações Unidas.

A partir dessa crítica, Boaventura de Sousa Santos propõe a concepção contra-hegemônica dos direitos humanos. Para o autor, a diferenciação entre hegemônico e contra-hegemônico só pode ser determinada e acessada contextualmente:

Como a concebo aqui, a hegemonia é um feixe de esquemas intelectuais e políticos que são vistos pela maioria das pessoas (mesmo por muitos dos que são negativamente afetados por ela) como fornecendo o entendimento natural ou único possível da vida social. Por outro lado, a contra hegemonia [sic] resulta de um trabalho organizado de mobilização intelectual e política contra a corrente, destinado a desacreditar os esquemas hegemônicos e fornecer entendimentos alternativos credíveis da vida social ${ }^{22}$.

Sob esse viés, os direitos humanos são compreendidos como uma noção intercultural e que deve estar em diálogo com outras noções de dignidade humana, contrapondo-se à perspectiva hegemônica dos direitos humanos que os concebem como "individualistas, seculares, culturalmente Ocidente-cêntricos, e Estado-cêntricos, quer quando visam controlar o Estado, quer quando pretendem tirar proveito dele"23. Nesse sentido, Santos advoga que as teologias pluralistas e progressistas podem exercer um importante papel na consolidação de uma cultura contra-hegemônica dos direitos humanos, uma vez que elas têm assumido uma postura de oposição à noção preponderante, submetendo esses direitos a um processo de reconstrução política e filosófica:

[...] os ativistas da luta por justiça socioeconômica, histórica, sexual, racial, cultural e pós-colonial baseiam frequentemente o seu ativismo e as suas reivindicações em crenças religiosas ou espiritualidades cristãs, islâmicas, hindus, budistas e indígenas. De certo modo, estas posições dão testemunho de subjetividades políticas que parecem ter abandonado o pensamento crítico ocidental e a ação política secular que dele decorre. Tais subjetividades combinam efervescência criativa e energia apaixonada e intensa com referências transcendentes ou espirituais que, longe de as afastarem das lutas materiais e bem terrenas por um mundo possível, mais profundamente as comprometem com estas ${ }^{24}$.

A distinção entre os espaços público e privado é posta em questão por esses grupos, assim como o confinamento da religião à esfera particular. Essa separação, elemento central no imaginário político ocidental, ocultaria relações de opressão tanto no plano da regulação social como na da emancipação social. Assim, a reivindicação da religião como elemento constitutivo da vida pública tem ganhado projeção nas lutas por justiça social em âmbito global.

22 SANTOS, 2014, p. 33.

${ }^{23}$ SANTOS, 2014, p. 11.

${ }^{24}$ SANTOS, 2014, p. 12-13. 
Em síntese, os direitos humanos concebidos criticamente e sob o viés contra-hegemônico possibilitam uma abertura para a dimensão religiosa a fim de contribuir para a tradução de outras lógicas interculturais e a abertura para o diálogo com outras semânticas de dignidade humana, sejam elas religiosas ou não. A compreensão e o alcance dos direitos humanos ampliam-se para além da dimensão sociocultural em que se originaram e trazem para o centro da sua pauta a importância do entendimento da diversidade e pluralidade religiosa nos processos de emancipação social. A dimensão religiosa, que, em um dado momento histórico, foi concebida como um empecilho para a garantia das liberdades civis nas repúblicas modernas, faz um movimento reverso, passando a integrar os movimentos de luta pela efetivação dos valores democráticos.

\section{Um novo paradigma de religião em uma época pluralista}

A religião tem muito a ver com os direitos humanos: a criação do Conselho Mundial de Igrejas cristãs coincide com a publicação da Declaração Universal dos Direitos Humanos, sendo o artigo 18 da versão final da Declaração resultado do trabalho desse movimento ecumênico. ${ }^{25}$ Muitas ações do ecumenismo cristão deram corpo aos ideais dos direitos humanos: o Conselho Latino-Americano de Igrejas interveio em regiões conflagradas da América, socorrendo vítimas dos conflitos e criando asilo para milhares de pessoas perseguidas; o projeto ecumênico "Brasil: tortura nunca mais" permitiu proteção e memória de vítimas da ditadura; o Conselho Mundial de Igrejas foi decisivo no enfrentamento do apartheid racista da África do Sul; como também foram importantes a "Década de Solidariedade com as Mulheres" e a "Década para Superar a Violência"

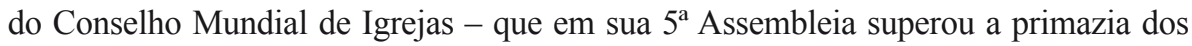
direitos individuais e tratou de "Estruturas injustas e lutas pela libertação".

Ao trazer a dimensão religiosa para o centro do debate sobre a reconstrução dos direitos humanos, é necessário não só o desenvolvimento de uma concepção contra-hegemônica desses direitos, mas também articular a esse processo uma abordagem que leve em consideração a multiplicidade do fenômeno religioso. Nesse sentido, o conceito de pluralismo religioso desenvolvido por Berger ${ }^{26}$ pode nos ser útil, posto que o conceito proposto possibilita captar o dinamismo dos movimentos religiosos frente aos desafios do mundo contemporâneo.

A definição de pluralismo proposta por Berger é de cunho sociológico, uma vez que ele vê esse fenômeno como um fato empírico na sociedade, experimentado por pessoas comuns:

[...] o pluralismo é uma situação social na qual pessoas de diferentes etnias, cosmovisões e moralidades vivem juntas pacificamente e interagem amigavelmente. [...] Faz pouco sentido falar de pluralismo, quando as pessoas não falam umas com as outras. [...] Para que o pluralismo desencadeie a sua plena dinâmica, deve haver conversação

\footnotetext{
25 TEIXEIRA, Faustino; DIAS, Zwinglio. Ecumenismo e diálogo inter-religioso: a arte do possível. São Paulo: Santuário, 2008. p. 87.

${ }^{26}$ Cf. BERGER, 2017.
} 
constante, não necessariamente entre iguais, mas prolongada no tempo e cobrindo uma ampla variedade de temas ${ }^{27}$.

Em síntese, o pluralismo acontece quando há conversação constante entre os diferentes. Essa conversação não precisa ocorrer, necessariamente, entre iguais, mas em um ambiente razoavelmente pacífico, em que o diálogo possa se efetivar. Apesar disso, o pluralismo não implica a ausência de conflitos, porém uma administração da diversidade. Isso possibilitaria o processo que o autor denomina de contaminação cognitiva, isto é, quando pessoas ou grupos passam a se influenciar mutuamente. O pluralismo faz com que esse processo se estabeleça de forma permanente na sociedade.

A contaminação cognitiva refere-se "ao que acontece quando as pessoas se veem diante de supostos fatos que contradizem aquilo em que elas acreditavam" 28 . As pessoas desenvolveriam uma série de estratégias para evitar a dissonância como, por exemplo, negar a validade da informação divergente, ataques ao portador da informação, remover os portadores da informação de cena ou retirar-se elas próprias do local, converter ou matar os dissonantes. No entanto, uma opção menos hostil também pode ocorrer: negociar com os dissonantes - e a isso Berger dará o nome de barganha cognitiva, a capacidade de relativizar os impactos da diferença:

[...] a relativização ocorre, pelo menos minimamente, quando alguém se comporta visivelmente de maneira diferente daquilo que o outro aceitava normalmente como sendo o comportamento apropriado. A relativização se intensifica se o desafiador verbalizar o desacordo. Assim, as várias formas de interação com diferentes cosmovisões e com os comportamentos que elas engendram iniciam um processo de relativização ${ }^{29}$.

Dito de outra forma, a relativização é o entendimento de que a realidade pode ser percebida e vivenciada de diferentes formas e o pluralismo provoca o tipo de situação em que isso se torna uma experiência permanente. O pluralismo, tomado nesse sentido, existiu sob diferentes formas ao longo da história (na Ásia Oriental, Índia Pré-Islâmica etc.). Outro fator que pode ser atrelado a isso é o que o pluralismo é um fenômeno que frequentemente acontece em contextos urbanos e de forte interação comercial, estando, portanto, correlacionado com elementos geográficos e econômicos.

$\mathrm{O}$ que contribuiu para que o pluralismo se tornasse um fenômeno globalizado foi, segundo Berger, o advento da modernidade, pois é nela que começa o processo de aceleração e catalisação das dinâmicas urbanas e econômicas. $\mathrm{O}$ autor defende que a modernidade trouxe os elementos que possibilitaram essa nova dinâmica, isto é, os avanços tecnológicos e científicos. A modernização levou a uma grande transformação na condição humana, passando do destino para a escolha. Todas as áreas da vida de um indivíduo que outrora foram tidas como certas, passam para o campo das escolhas pessoais. A fim de entender esse processo de escolhas em expansão, Berger recor-

$\begin{array}{ll}{ }_{27} & \text { BERGER, 2017, p. } 20 . \\ { }_{28} & \text { BERGER, 2017, p. } 20 . \\ & \\ 29 & \text { BERGER, 2017, p. } 23 .\end{array}$ 
re aos trabalhos do sociólogo Arnold Gehlen. O argumento desenvolvido por Gehlen é o de que para compensar a pobreza dos instintos humanos - em comparação com os dos demais animais - nós desenvolvemos as instituições. São elas que fornecem diretrizes de ação que os nossos instintos não podem oferecer; elas funcionam como uma área de estabilidade em que o indivíduo pode agir sem a necessidade de muita reflexão, uma vez que toma como certo o conteúdo de suas ações e, simultaneamente, as instituições tornam possível outra área na qual o indivíduo estaria livre para fazer suas escolhas. A essas duas áreas Gehlen chamou de plano de fundo (background) e primeiro plano (foreground) da vida social humana. O plano de fundo seria fortemente institucionalizado enquanto o primeiro plano seria desinstitucionalizado. O plano de fundo corresponderia ao reino do destino, o primeiro plano ao reino das escolhas. Uma maneira que Berger usa para explicar esse conceito de instituições é referir-se a elas como gatilhos (estímulos) artificias que levariam um determinado instinto para a consciência, provocando um comportamento adequado para uma determinada situação ou contexto.

Quando o plano institucional passa a ser verbal e comportamentalmente questionado, há desafios para a estabilidade da instituição. A esses desafios Gehlen chamou de desinstitucionalização. Peter Berger argumenta que essa força de ruptura, com o tempo, tende a se acomodar aos programas institucionais. Segundo o autor, Max Weber tinha uma expressão para esse fenômeno, rotinização do carisma: "Rotinização [...] significa cotidianização. O carisma é a força que desafia e rompe as rotinas cotidianas. Ele não pode durar; acabam surgindo novos padrões institucionais" ${ }^{\text {"30 }}$.

Berger ressalta que o pluralismo não é o único vetor da multiplicação de escolhas, embora seja um elemento muito importante. Na verdade, ele contribui de forma substancial na expansão do primeiro plano à custa do plano de fundo:

Gehlen compreendeu algo mais a respeito das instituições: o fato de que a sua desconstrução provoca primeiro um estimulante sentido de libertação. [...] Depois de algum tempo, contudo, a vertigem da libertação abre caminho para uma inquietação crescente. [...] Agora se busca uma nova libertação, uma libertação da antiga libertação que aboliria as velhas coações institucionais. O que se segue tipicamente é a reconstrução de instituições, sejam elas antigas ou novas ${ }^{31}$.

Sob esse viés, o pluralismo relativiza e, consequentemente, enfraquece certezas às quais outrora os seres humanos estavam acostumados. Dois movimentos de reação à relativização surgem nesse cenário: o fundamentalismo e o relativismo.

O fundamentalismo é um esforço para restaurar a certeza ameaçada. [...] há fundamentalismos reacionários e progressistas. O que todos esses projetos têm em comum é uma promessa ao convertido em potencial: "Junte-se a nós, e você terá a certeza que há muito você deseja". [...] O relativismo pode ser definido simplesmente como a

${ }^{30}$ BERGER, 2017, p.30-31.

${ }^{31}$ BERGER, 2017, p. 32-33. 
admissão da relatividade; isto é, a relativização que de fato ocorreu é festejada como uma forma superior de conhecimento. Não se pode ter certeza de nada, porque não há nenhuma verdade cognitiva absoluta. [...] A experiência da relatividade, que aterroriza os fundamentalistas e da qual eles procuram escapar, agora se torna uma visão da qual se podem orgulhar e aplicar à prática da vida. ${ }^{32}$

Apesar disso, Berger reforça que a maioria das pessoas na sociedade não é constituída por fundamentalistas ou relativistas - muito menos está preocupada com a teorização dessas questões -, mas por pessoas que vivem num meio-termo entre negar e louvar a modernidade, elas vivem na situação do pluralismo administrando-a pragmaticamente. Essa maneira de viver também não escapa à lógica do relativismo, podendo se demonstrar duradoura, mas também sendo facilmente dissolvida. O problema do pluralismo seria a manutenção de um meio-termo entre fundamentalismo e relativismo. Nesse contexto, a religião tem um importante papel, pois ela "determina a maneira como se olha para o mundo e como se deveria viver. É por isso que a relação entre religião e pluralismo deveria ser de interesse de todos, independentemente das crenças religiosas ou da ausência delas" 33 .

Tal capacidade ganha esses contornos na modernidade, embora o autor ressalte que a capacidade humana de administrar diferentes relevâncias já existisse desde o início da espécie humana - como o homem da caverna que crê que o machado é um ente sagrado, mas que procura sempre deixá-lo bem afiado para o uso. Com isso, Peter Berger reforça a ideia de que os indivíduos operam em diferentes realidades. O que marcaria nosso tempo, portanto, não seria a descrença, mas a dúvida, isto é, a implicação de que a cada qual precisa se decidir a afirmar suas supostas certezas em meio a outras que, a princípio, estão disponíveis. Esse cenário provoca duas reações: "o relativismo, que produz um credo a partir da incerteza, e o fundamentalismo, que pretende restaurar o sentido da certeza" 34 . Ambos os movimentos seriam perigosos para os indivíduos e para a sociedade, pois, para o autor, levariam a dois extremos (niilismo/fatalismo). A tensão entre esses dois polos deveria ser administrada para que um não se sobreponha ao outro, nem aos indivíduos nem à sociedade, isto é, deve haver uma administração da dúvida.

\section{Uma concepção transreligiosa do humano e do humanizante}

A esse paradigma pluralista, e consequente necessidade de um contrato epistemológico da administração de controvérsias, corresponde um modelo transdisciplinar de produção do conhecimento: ele não descarta as disciplinas científicas, mas se move entre, através e além delas. A transdisciplinaridade transgride as fronteiras de cada ciência

\footnotetext{
32 BERGER, 2017, p. 34- 37.

33 BERGER, 2017, p. 45.

34 BERGER, 2017, p. 131.
} 
disciplinar e constrói um novo conhecimento "através" das ciências, um conhecimento integrado em função da humanidade, resgatando as relações de interdependência. ${ }^{35}$

A transdisciplinaridade operacionaliza uma nova forma, complexa, de ver e entender a natureza, a vida e a humanidade. Ela engendra uma lógica ternária para administração de controvérsias e estimula a construção do saber através de campos inter ou transdisciplinares. Isso porque busca a unidade do conhecimento, entre e além das disciplinas científicas, incluindo a nossa subjetividade e as sabedorias tradicionais, para ajudar a encontrar sentido na existência. A transdisciplinaridade reivindica a centralidade da vida em toda discussão, propondo uma mudança na compreensão do conhecimento: como relação entre sujeitos e objetos, atenta ao contraditório em tudo, mas aberta à sua superação em outros níveis de realidade - pela inclusão de um Terceiro termo lógico. ${ }^{36}$

Isso tem consequências para o movimento de encontro e diálogo entre tradições espirituais e religiosas, bem como para a pesquisa das religiões e religiosidades, pois tal modelo de conhecimento, complexo e transdisciplinar, gerou a lógica do Terceiro Incluído que, debruçada sobre o fenômeno das religiões e as contradições que surgem do seu pluralismo, remete à busca de um outro nível de realidade, àquela ética do amor, que pode religar crentes doutrinalmente antagônicos em uma fé que se faz silêncio místico ou atitude de cuidado pelos outros e pelo nosso meio e permite o acesso ao sagrado, aos portais para o mistério da vida e da realidade, acesso à zona de resistência misteriosa que religa sujeito e objeto. Por aí, analogicamente, passa a experiência do divino mais autêntico, por entre e para além das religiões.

Com base nesses princípios e modelos, advogamos que as teologias pluralistas e progressistas, das diversas tradições espirituais religiosas, podem exercer um importante papel na consolidação de uma cultura contra-hegemônica dos direitos humanos. Acreditamos que o diálogo inter-religioso, que daí decorre, é chamado a criar ambiência mística de compromisso, entre e para além dos caminhos de fé, com a frente ecumênica e ecológica do cuidado com a Casa Comum e do respeito ao seu guardião humano.

E podemos logo aduzir quatro laboratórios que confluem para essa contribuição das espiritualidades em vista da defesa, entre e além das diversas espiritualidades, da dignidade humana e da justiça socioambiental, da humanização da existência. Dois deles são representativos de movimentos deflagrados por estudiosos das religiões e os outros dois são resultantes de eventos de promoção do diálogo inter-religioso.

O primeiro, resultante dos esforços de Hans Küng e da sua construção de uma teologia inter-religiosa e de uma ética intercultural, está expresso na Declaração de Ética Mundial do Parlamento das Religiões Mundiais, que já em 1993 defendeu que não há nova ordem mundial sem uma ética mundial, que o desafio básico é que todo ser humano tem que ser tratado de forma humana, em vista do que devemos assumir quatro preceitos inamovíveis: compromisso com uma cultura da não violência e do

${ }^{35}$ Cf. NICOLESCU, 1999.

${ }^{36}$ ARAGÃO, Gilbraz; SOUZA, Mailson. Transdisciplinaridade, o campo das Ciências da Religião e sua aplicação ao Ensino Religioso. Estudos Teológicos, v. 58, n. 1, p. 42-56, 2018. p. 44. 
temor diante da vida, compromisso com uma cultura da solidariedade e uma ordem econômica justa, compromisso com uma cultura da tolerância e uma vida de veracidade, compromisso com uma cultura da igualdade de direitos e do companheirismo entre homem e mulher.

Reiteradas vezes, e em diversos lugares deste mundo, observamos que líderes e adeptos de religiões instigam à agressão, ao fanatismo, ao ódio e à xenofobia; e inspiram e legitimam até mesmo confrontos sangrentos e marcados pela violência. Usurpa-se a religião para fins meramente voltados à conquista do poder político, até o extremo da guerra. Isso nos causa grande repugnância. Condenamos todos esses desenvolvimentos e declaramos que isso não tem que ser assim. Já existe uma ética capaz de oferecer orientação diversa à desses desdobramentos globais funestos. Embora essa ética não ofereça soluções diretas para todos os imensos problemas mundiais, oferece a base moral para uma ordem individual e global melhor: uma visão capaz de afastar homens e mulheres do desespero, e as sociedades, do caos. Somos homens e mulheres que professam os mandamentos e práticas das religiões mundiais. Afirmamos já haver um consenso entre as religiões, capaz de constituir a base para uma ética mundial: um consenso fundamental mínimo, no que diz respeito a valores obrigatórios, parâmetros inamovíveis e atitudes morais básicas. ${ }^{37}$

O segundo, fruto da militância de Karen Armstrong e da sua história comparada das religiões, está expressa na Carta da Compaixão e nos diversos movimentos e intervenções organizados, desde 2009, em torno a uma regra de ouro comum às principais religiões do mundo:

O princípio da compaixão é o cerne de todas as tradições religiosas, éticas e espirituais, conclamando-nos a tratar sempre todos os outros da mesma maneira como gostaríamos de ser tratados. A compaixão nos impele a trabalhar incessantemente com o intuito de aliviarmos o sofrimento do nosso próximo, o que inclui todas as criaturas, de nos destronarmos do centro do nosso mundo e, no lugar, colocar os outros, e de honrarmos a santidade inviolável de todo ser humano, tratando todas as pessoas, sem exceção, com absoluta justiça, equidade e respeito ${ }^{38}$.

O terceiro, oriundo da Conferência das Religiões do Mundo, que reuniu estudiosos das religiões em 2016 em Montreal, para pensar no fator religioso depois do "11 de setembro" pelo mundo afora, promulgou uma "Declaração Universal de Direitos Humanos pelas Religiões do Mundo", em cujo preâmbulo defende:

Considerando que é essencial incluir as religiões do mundo como recursos positivos em matéria de direitos humanos; considerando que as comunidades de fé determinaram

${ }^{37}$ PARLAMENTO DAS RELIGIÕES MUNDIAIS. Declaração de Ética Mundial. Chicago: PRM, 1993. Disponível em: <https://www.weltethos.org/1-pdf/10-stiftung/declaration/declaration_portuguese.pdf>. Acesso em: 19 maio 2019. p. 9.

${ }^{38}$ COUNCIL OF CHARTER FOR COMPASSION. Carta para a compaixão. Bainbridge Island: CFC, 2009. Disponível em: <https://charterforcompassion.org/charter>. Acesso em: 19 maio 2019. p. 1. 
que levar a vida plenamente em consideração abrange o bem-estar material, bem como social, cultural, comunitário, ambiental e espiritual; considerando que as religiões instam os seres humanos a criar e sustentar uma sociedade justa, onde os direitos humanos fundamentais são promovidos e protegidos; considerando que as religiões do mundo ensinam a verdade fundamental sobre a unidade da família humana; considerando que as diversas comunidades que compõem a população mundial devem intercambiar não apenas ideias, mas também ideais; considerando que a base de consciência das pessoas de fé foi afetada devido ao fracasso de indivíduos e autoridades das religiões do mundo em questões de defesa dos direitos humanos, e as atrocidades e ferimentos dos direitos humanos que os mesmos cometeram em nome da religião, incluindo atos de terrorismo; considerando que certas formas de extremismo ideológico violento, tanto religioso quanto secular, continuam a ameaçar o exercício dos direitos humanos; considerando que os direitos humanos de uma pessoa merecem proteção independentemente dos deveres que essa pessoa cumpre e que a concepção e aplicação dos mesmos mantêm uma relação integral com o exercício de deveres morais e legais; considerando que as religiões reconhecem que o exercício pleno dos direitos humanos depende do cumprimento de deveres em diferentes níveis da sociedade; considerando que a falta de reconhecimento e reparação das injustiças cometidas contra as vítimas de racismo, sexismo, discriminação religiosa, nacionalismo, classismo, castrismo e qualquer outra forma de opressão vai contra o exercício pleno e a prosperidade dos direitos humanos; a seguinte Declaração Universal dos Direitos Humanos pelas Religiões do Mundo é proposta como complemento à Declaração Universal dos Direitos Humanos adotada pela Assembleia Geral das Nações Unidas ${ }^{39}$.

O quarto resulta do documento firmado em 2019 no encontro do papa Francisco com o grande imã de Al-Azhar, Ahmad Al-Tayyib. Eles assinaram uma declaração conjunta que marca a história das relações entre o cristianismo e o islamismo, convidando os fiéis das maiores religiões do mundo para um caminho compartilhado de combate à miséria, à exploração e à degradação:

A fé leva o crente a ver no outro um irmão que se deve apoiar e amar. Da fé em Deus, que criou o universo, as criaturas e todos os seres humanos - iguais pela Sua Misericórdia -, o crente é chamado a expressar esta fraternidade humana, salvaguardando a criação e todo o universo e apoiando todas as pessoas, especialmente as mais necessitadas e pobres. Partindo deste valor transcendente, em vários encontros dominados por uma atmosfera de fraternidade e amizade, compartilhamos as alegrias, as tristezas e os problemas do mundo contemporâneo, a nível do progresso científico e técnico, das conquistas terapêuticas, da era digital, dos mass-media, das comunicações; a nível da pobreza, das guerras e das aflições de tantos irmãos e irmãs em diferentes partes do mundo, por causa da corrida às armas, das injustiças sociais, da corrupção, das desigualdades, da degradação moral, do terrorismo, da discriminação, do extremismo e de muitos outros motivos. De tais fraternas e sinceras acareações que tivemos e do

39 GLOBAL CONFERENCE ON WORLD'S RELIGIONS. Universal Declaration of Human Rights by the World's Religions. Montreal: GCWR, 2016. Disponível em: <http://worldsreligions2016.org/>. Acesso em: 19 maio 2019. p. 6. 
encontro cheio de esperança num futuro luminoso para todos os seres humanos, nasceu a ideia deste "Documento sobre a Fraternidade Humana"

Vale lembrar que, agora, católicos integralistas e evangélicos fundamentalistas vão se reunir em Roma ${ }^{41}$, na porta do papa Francisco e levantando a bandeira mal costurada do papa anterior, para celebrar exatamente o contrário e contrapor à fraternidade humana a honra nacionalista e neoconservadora, pretensamente abençoada pelo "deus cristão": uma nova santa aliança contra o islã e os muçulmanos, contra as outras culturas e religiões da Terra.

Até por conta disso, fica o convite aos estudiosos das religiões e aos militantes dos direitos humanos para conhecerem a aprofundarem as interfaces profícuas que podem ser desenvolvidas entre as espiritualidades e os humanismos da nossa história comum. Todos somos luz e treva, em comunitária evolução. Nenhum triunfalismo, religioso ou científico, pode ter lugar em um novo paradigma de realidade e de conhecimento, onde se procura defender a vida de todos.

\section{Considerações finais}

Apresentamos neste artigo o desafio de uma tradução transcultural das teologias políticas, tratando de apontar a possível vinculação de uma concepção contra-hegemônica do movimento de direitos humanos aos grupos religiosos libertários das várias tradições espirituais. Buscamos aprofundar a questão por que nosso tempo turbulento de transformação sociopolítica, em que o fator religioso tem sido decisivo, demanda um maior envolvimento crítico dos estudiosos de religião no espaço público, bem como novas relações entre grupos humanistas seculares e tradições de fé esclarecida.

Para defender nossa tese, desenvolvemos aqui uma breve genealogia do movimento de direitos humanos, explicitando a necessidade e possibilidade de uma concepção contra-hegemônica dos seus fundamentos político-filosóficos. Discorremos a seguir sobre a situação de pluralismo religioso na aldeia global contemporânea e da necessidade (e, novamente, da possibilidade) de um contrato epistemológico para administração das controvérsias que surgem da diversidade entre as (e dentro das) atitudes e os caminhos religiosos. Nesse sentido, apontamos para a lógica do Terceiro Incluído, para o humano e seu mistério, para a ética e a mística, que estão gerando uma agitação transreligiosa de diálogo entre tradições espirituais, do qual apresentamos alguns exemplos, e que transbordam em cuidado pelo humano em seu contexto ambiental e cultural.

Esperamos ter iniciado, assim, um percurso reflexivo que colabore para que os direitos humanos exerçam melhor o papel de gramática da dignidade humana, porque pensados sob uma perspectiva contra-hegemônica, partindo das lutas por justiça

40 PAPA FRANCISCO E AHMAD AL-TAYYIB. Documento sobre a fraternidade humana. Abu Dhabi; Vatican, 2019. Disponível em: <https://press.vatican.va/content/salastampa/it/bollettino/ pubblico/2019/02/04/0097/00199.html\#port>. Acesso em: 19 maio 2019. p. 3.

${ }^{41} \mathrm{Cf}$. <http://www.ihu.unisinos.br/595928-o-desafio-da-conferencia-neoconservadora-a-poucos-passos-dovaticano>. Acesso em: 19 fev. 2020. 
socioambiental, para as quais as religiões, por meio de suas pastorais progressistas e suas teologias pluralistas, podem fornecer um ponto de intersecção e motivação, de justificação não aquém da razão, mas além dela.

\section{Referências}

ARAGÃO, Gilbraz; SOUZA, Mailson. Transdisciplinaridade, o campo das Ciências da Religião e sua aplicação ao Ensino Religioso. Estudos Teológicos, v. 58, n. 1, p. 42-56, 2018.

BBC. Estamos indo em direção a um mundo sem direitos humanos? BBC Brasil. 07 jan. 2017. Disponível em: <https://www.bbc.com/portuguese/internacional-38510456>. Acesso em: 20 jan. 2020.

BENEVIDES SOARES, Maria. Cidadania e Direitos Humanos. CP Cadernos de Pesquisa, Fundação Carlos Chagas, São Paulo, n. 104, p. 39-46, jul. 1998. Disponível em: <publicacoes. fcc.org.br/ojs/index.php/cp/article/view/715/731>. Acesso em: 05 maio 2019.

BERGER, Peter. Os múltiplos altares da modernidade: rumo a um paradigma da religião numa época pluralista. Petrópolis: Vozes, 2017.

BOFF, Leonardo. Saber cuidar: ética do humano, compaixão pela Terra. Petrópolis: Vozes, 1999. BRASIL. Constituição (1988). Brasília: Senado Federal, 2015.

COUNCIL OF CHARTER FOR COMPASSION. Carta para a compaixão. Bainbridge Island: CFC, 2009. Disponível em: <https://charterforcompassion.org/charter>. Acesso em: 19 maio 2019. GLOBAL CONFERENCE ON WORLD'S RELIGIONS. Universal Declaration of Human Rights by the World's Religions. Montreal: GCWR, 2016. Disponível em: <http://worldsreligions2016. org/>. Acesso em: 19 maio 2019.

LOGHI, Carla. Direitos Humanos e cidadania. Projeto História, v. 51, p. 7-14, set./dez. 2014. Disponível em: <revistas.pucsp.br/index.php/revph/article/viewFile/24045/17587>. Acesso em: 19 maio 2019.

NICOLESCU, Basarab. O manifesto da transdisciplinaridade. São Paulo: Triom, 1999.

PAPA FRANCISCO E AHMAD AL-TAYYIB. Documento sobre a fraternidade humana. Abu Dhabi; Vatican, 2019. Disponível em: <https://press.vatican.va/content/salastampa/it/bollettino/ pubblico/2019/02/04/0097/00199.html\#port>. Acesso em: 19 maio 2019.

PARLAMENTO DAS RELIGIÕES MUNDIAIS. Declaração de Ética Mundial. Chicago: PRM, 1993. Disponível em: <https://www.weltethos.org/1-pdf/10-stiftung/declaration/declaration portuguese.pdf>. Acesso em: 19 maio 2019.

PIOVESAN, Flávia. Direitos humanos e direito constitucional internacional. Caderno de direito constitucional. Escola de magistratura do Tribunal Regional Federal da 4a região, 2006.

UNITED NATIONS. ABC: teaching human rights, practical activities for primary and secondary schools. Gevena: United Nations Publications, 2004.

SANTOS, Boaventura de Sousa. Se Deus fosse um ativista dos direitos humanos. São Paulo: Cortez, 2014.

TEIXEIRA, Faustino; DIAS, Zwinglio. Ecumenismo e diálogo inter-religioso: a arte do possível. São Paulo: Santuário, 2008. 